Carlos Carmona Santander

Profesor Titular de Derecho Administrativo

Universidad de Chile

\title{
El vicio de la desviación de poder en los actos administrativos*
}

\author{
Camilo Lledó Veloso y José Pardo Donoso
}

Editorial Thomson Reuters, Legalpublishing, Santiago, 2013

\section{Agradecimientos}

En primer lugar, quiero agradecer a Camilo Lledó y a José Pardo la amabilidad que tuvieron al invitarme a presentar este libro. También quiero tomarme la atribución de agradecer a nombre de los profesores de Derecho Administrativo que lo hayan hecho y que lo hayan publicado.

Desde luego, porque con libros como éste salimos de los temas que nos tienen atrapados a los profesores (nulidad, sanciones administrativas, etc.). Siempre los mismos. Entonces, que dos alumnos rompan ese circuito permite que entre aire fresco a la disciplina y así avancemos.

Enseguida, saldamos una deuda pendiente. La doctrina nacional debe abordar ciertos temas para ser tal, para tener la madurez dogmática necesaria.

Finalmente, porque el tratamiento profundo y serio de este tema, prácticamente inabordado en nuestro Derecho, marca un hito. Este libro, me atrevo a sostenerlo aquí, es un antes y un después en la desviación de fin.

Cuando se profundizan las instituciones propias del derecho público, dejamos de mirar éstas desde el planeador, es decir desde una mirada rápida y superficial, para entrar a una mirada microscópica, profunda, crítica. También mejoramos el debate y la discusión, dejamos de utilizar terminología general. Entramos al uso de categorías dogmáticas. Y permitimos que los asuntos sean discutidos en un examen más técnico e incisivo.

El Derecho Administrativo, con libros como el de Camilo y José, tiene asegurada su renovación. Cuando jóvenes cultores de la disciplina dan un paso gigante, firme, desafiante, todos los profesores más antiguos debemos sentirnos motivados y agradecidos.

\footnotetext{
* Presentación del libro en la Facultad de Derecho de la Universidad de Chile, el 26 de agosto de 2014.
} 
De más está decirlo, los autores de la monografía que presentamos hoy fueron destacados alumnos y ayudantes y son, en la actualidad, destacados profesionales.

\section{Cuestiones previas}

Antes de entrar en materia, quiero resaltar algunas cosas:

1. El título del libro es mezquino. Nadie se alarme. Trata sobre la desviación de fin. Lo que sucede es que trata más que la desviación de fin. Por una parte, porque hace toda una tipología de los vicios del acto administrativo. Para ello, los autores establecen los elementos del acto administrativo: el elemento subjetivo, el objetivo, el causal y el formal. Asociados a cada uno de ellos, están los vicios del acto administrativo. Dicha clasificación la hacen separada de la nulidad de derecho público. Por lo mismo, tiene una funcionalidad que excede dicha acción contenciosa administrativa. Por la otra, porque abordan otra serie de materias tangenciales a su tema central, pero igualmente relevantes, como la teoría de las potestades y de instituciones afines a la desviación de fin.

2. Otra precisión antes de comenzar, es que los autores eligen un tema emblemático del Derecho Administrativo. Desviación de fin y Derecho Administrativo nacieron juntos. El recurso por exceso de poder es el instrumento a través del cual el Consejo de Estado francés desarrolló y consolidó el Derecho Administrativo continental. En este sentido, abordar este tema es abordar un clásico.

3. La tercera precisión inicial es que abordar la desviación de fin es meterse en las patologías de los actos. Los médicos no tienen problema en estudiar las enfermedades. Pero a los abogados los forman como que los vicios, de cualquier tipo que sean, son una anormalidad. Y, por lo tanto, sin la relevancia merecida. Venciendo ese prejuicio, Camilo y José entran en una de las patologías clásicas de los vicios del acto administrativo.

Pero lo hacen, por una parte, con la metodología que siempre tuvo el vicio en el derecho administrativo francés. Es decir, los autores abordan el tema con sistematicidad y precisión. Y, por la otra, lo enmarcan adecuadamente en el tema del control del acto administrativo. El vicio tiene relevancia en la medida que permite reclamar de él ante la propia Administración, ante la Contraloría o ante los tribunales.

1. La última precisión inicial es que el libro tiene varias virtudes. Por de pronto, la claridad. No obstante la complejidad en ciertos apartados, los autores tienen la cortesía de no confundir al lector y ayudarlo a comprender. Lo sofisticado no tiene por qué ser necesariamente enredado. Enseguida, tiene la virtud de la precisión. Los autores van al punto. No se distraen en cosas accidentales. También destaca la profundidad. Los autores no escabullen los problemas. Van planteando solución, abriendo caminos, transmitiendo certezas. Finalmente, el manejo bibliográfico. Los autores revisaron la principal bibliografía existente sobre la materia, concentrándose en los clásicos. Y le sacaron enorme partido a esos textos. 


\section{La metodología}

Lo primero que quiero destacar del libro es su metodología de análisis. Utiliza el método conocido por todos: conceptualizar una institución, establecer sus requisitos, examinar el derecho comparado y recopilar la jurisprudencia.

En el concepto de la desviación de fin, esto se ve bien reflejado, pues los autores utilizan una doble variable. Por un lado, la de entregar un concepto positivo del vicio de la desviación de fin (infracción de las finalidades establecidas para el acto administrativo por la norma reguladora de la potestad pública administrativa). Por otro, la de entregar un concepto negativo, diferenciando el vicio de desviación de fin de otras instituciones que se le acercan, como el abuso de derecho, el fraude a la ley o la desviación de procedimiento.

Cuando se analiza el concepto de desviación de fin, se recurre a la doctrina comparada (los autores franceses, italianos y españoles desfilan por las páginas del libro) y la relativamente escasa doctrina nacional.

\section{Planteamientos centrales}

1. Entrando ahora a los planteamientos centrales del libro, es necesario partir por señalar que salvo la alusión que hace el artículo $2^{\circ}$ de la LOCBGAE, cuando se dice que se puede reclamar de todo abuso o exceso de poder, nuestro ordenamiento jurídico no tiene una identificación del vicio como lo hace la ley espańola del contencioso-administrativo (ejercicio de potestades administrativas para fines distintos de los fijados por el ordenamiento jurídico).

Por lo tanto, los autores tienen que abordar de partida el concepto de desviación de fin. Y lo hacen de dos maneras.

En primer lugar, indican que en la desviación de fin hay una infracción de las finalidades establecidas en el acto por la norma reguladora (pág. 249-250).

En segundo lugar, los autores hacen una tipología de cuándo se produce esta infracción. Para eso, y en éste está seguramente el gran aporte de la tesis, unen dos elementos del acto administrativo. De un lado, lo que ellos llama, finalidad subjetiva, asociada a los motivos o móviles del acto. Y, del otro, la finalidad objetiva, es decir, el resultado perseguido o producido por el acto.

Esta mezcla supera la tradicional forma de explicar las tres modalidades del vicio de desviación de fin, en que la potestad se encamina hacia fines distintos, tanto públicos como privados. Estas tres modalidades, como se sabe, son: la actuación con una finalidad personal (venganza, maldad, lucro); la actuación con una finalidad pública, pero distinta a la prevista por la ley; y la actuación que persigue beneficiar a terceros o a grupos de terceros, pero no a la administración.

La mezcla que hacen los autores les permite ampliar la tipificación de los casos en que hay desviación de fin, de tres a seis. Así, hay desviación de fin, sostienen los autores, cuando el acto no está motivado o está falsamente motivado; también cuando hay un móvil torcido tras un acto adecuadamente motivado; asimismo, hay un acto adecuadamente fundamentado, con un resul- 
tado indeseado por el ordenamiento jurídico; también cuando el acto es fundado pero su motivo es falso o torcido; además, existe cuando la motivación se confunde con el móvil y, finalmente, cuando hay actos cuyos resultados son contrarios a los fines de la norma atributiva de la potestad.

2. Otro aspecto medular de la tesis, es que los autores toman posición respecto de la discusión sobre la naturaleza jurídica que debe reunir la distorsión del fin. Recordemos que hay dos posiciones. De un lado, está la posición objetiva. Esta sostiene que el fin de la norma implica una variable de apreciación objetiva, no de intencionalidad de la gente. El vicio afecta un elemento reglado del acto: el fin. La otra, es la posición subjetiva, que resalta la intencionalidad del sujeto administrativo para la configuración de este fin. La potestad se ejerce con la intención de servir a un fin distinto al que la legitima y que es la causa o razón del acto.

Como los propios autores indican, convocando a Garrido Falla, la discusión es si existe una "moralidad administrativa", que sobrepasa la legalidad, o si la desviación de poder es pura y simplemente un caso de violación de ley.

En esta disyuntiva, los autores toman posición. Para ellos, la finalidad se aprecia en forma objetiva, contrastando la norma con elementos tales como su historia, la normativa que la rodea o los principios generales de derecho público. Lo que la gente piensa y pretende señalar debe permanecer, concluyen, en el ámbito extrajurídico.

3. El tercer aspecto en que los autores dan un salto cualitativo, es en relación a la prueba del vicio. En este sentido, los autores sostienen que hay dos maneras de hacerlo, constatando la dificultad que la prueba de este vicio conlleva. Por una parte, aportando elementos determinantes que acrediten la intención de desviar la potestad. Por otro lado, pueden utilizarse elementos indiciarios, ponderándolos con otros elementos como el correcto desempeño de la función pública, el interés público, el bien común, la gravedad del daño justificado y la continuidad del servicio.

4. Finalmente, quiero resaltar el capítulo destinado a la recopilación y sistematización de jurisprudencia que hacen los autores. Para ello recurren a la jurisprudencia de la Contraloría, a la jurisprudencia de nuestros tribunales y a la jurisprudencia del derecho comparado.

Este es, a no dudarlo, el mejor barrido que se ha hecho sobre el tema en nuestro país. El capítulo sirve no sólo para demostrar las dificultades que tiene nuestra jurisprudencia al emplear esta categoría dogmática, sin el aplomo con que se mueven en otras áreas, sino también para dos cosas adicionales. De un lado, la decantación, en contraste, que la concepción de este vicio tiene en la jurisprudencia de la Contraloría; y del otro, para explicar cómo este vicio puede ser un instrumento destinado a controlar con eficacia el acto administrativo.

\section{Palabras finales}

No me queda más que reiterar a Camilo y a José por su tremendo aporte. Le pusieron nombre-el de ustedes-al estudio de este vicio. Asimismo, se unen a los grandes profesores de otras latitudes que han comenzado su carrera académica con el estudio de este vicio, como lo hicieron Carmen Chinchilla y Lorenzo Martín Retortillo en España. También reiterar la calidad dogmática del estudio. 
Felicito a Jaime Jara por haber guiado a estos brillantes alumnos en este esfuerzo. Se ve la mano. El profesor Jara acaba de publicar también un notable artículo sobre este mismo vicio, que puede leerse con total independencia, pero en diálogo, de este trabajo que presentamos.

También la Escuela debe sentirse orgullosa de que sus alumnos enfrenten el desafío de investigar y desarrollar estos temas. Mientras eso suceda, esta Escuela estará viva, porque significa que tiene sangre nueva que circula por estas viejas estructuras.

Bien por el Derecho Administrativo, porque se pone pantalones largos con esta contundente memoria.

Camilo y José: ¡Los felicito! Porque entran por la puerta ancha a la profesión y al mundo académico. No queda más que darles un gran abrazo de bienvenida y de buenaventura.

Y por supuesto, a quienes no lo han hecho, compren el libro. Vale la pena tenerlo y consultarlo, porque se aprende, entretiene y aporta. 